\title{
Advanced Catalysts for the Ambient Temperature Oxidation of Carbon Monoxide and Formaldehyde
}

\author{
Tim Nalette ${ }^{1}$, Christopher Eldridge ${ }^{2}$, Ping Yu, $\mathrm{PhD}^{3}$ \\ Hamilton Sundstrand Space Systems International, Windsor Locks, CT, 06096 \\ Gokhan Alptekin, $\mathrm{PhD}^{4}$ \\ TDA Research, Inc., Wheatridge, CO, 80033 \\ and \\ John Graf, $\mathrm{PhD}^{5}$ \\ NASA Johnson Space Center, Houston, TX, 77058
}

\begin{abstract}
The primary applications for ambient temperature carbon monoxide (CO) oxidation catalysts include emergency breathing masks and confined volume life support systems, such as those employed on the Shuttle. While Hopcalite is typically used in emergency breathing masks for terrestrial applications, in the 1970s, NASA selected a $2 \%$ platinum (Pt) on carbon for use on the Shuttle since it is more active and also more tolerant to water vapor.
\end{abstract}

In the last 10-15 years there have been significant advances in ambient temperature CO oxidation catalysts. Langley Research Center developed a monolithic catalyst for ambient temperature $\mathrm{CO}$ oxidation operating under stoichiometric conditions for closed loop carbon dioxide $\left(\mathrm{CO}_{2}\right)$ laser applications which is also advertised as having the potential to oxidize formaldehyde (HCHO) at ambient temperatures. In the last decade it has been discovered that appropriate sized nano-particles of gold are highly active for CO oxidation, even at subambient temperatures, and as a result there has been a wealth of data reported in the literature relating to ambient/low temperature $\mathrm{CO}$ oxidation.

In the shorter term missions where $\mathrm{CO}$ concentrations are typically controlled via ambient temperature oxidation catalysts, formaldehyde is also a contaminant of concern, and requires specially treated carbons such as Calgon Formasorb as untreated activated carbon has effectively no HCHO capacity. This paper examines the activity of some of the newer ambient temperature $\mathrm{CO}$ and formaldehyde (HCHO) oxidation catalysts, and measures the performance of the catalysts relative to the NASA baseline Ambient Temperature Catalytic Oxidizer (ATCO) catalyst at conditions of interest for closed loop trace contaminant control systems.

\section{Background}

With the advent of closed cycle $\mathrm{CO}_{2}$ lasers, a considerable body of literature exists related to low temperature $\mathrm{CO}$ oxidation catalysts. The high energy plasma of the laser results in decomposition of $\mathrm{CO}_{2}$ into stoichiometric quantities of $\mathrm{CO}$ and oxygen $\left(\mathrm{O}_{2}\right)$ which subsequently results in rapid power loss. To mitigate this phenomenon, low temperature $\mathrm{CO}$ oxidation catalysts have been developed to recombine the $\mathrm{O}_{2}$ and $\mathrm{CO}$, thereby maintaining the power output of the laser. While this application is targeting stoichiometric concentrations of $\mathrm{CO}$ and $\mathrm{O}_{2}$, more recently some of these catalysts are being evaluated for ambient temperature oxidation of $\mathrm{CO}$ and $\mathrm{HCHO}^{1-2}$.

\footnotetext{
${ }^{1}$ Chief, Advanced Technology, Space Systems, One Hamilton Road/1A2-W66.

${ }^{2}$ Senior Advanced Systems and Technology Engineer, Space Systems, One Hamilton Road/1A2-W66.

${ }^{3}$ Senior Advanced Technology Engineer, Space Systems, One Hamilton Road/1A2-W66.

${ }^{4}$ Senior Project Manager, TDA Research, 12345 W. $52^{\text {nd }}$ Avenue.

${ }^{5}$ Research Engineer. Crew and Thermal Systems Division, 2101 NASA Parkway/EC5.
} 
Much of the research related to $\mathrm{CO}_{2}$ lasers has focused on platinum/tin-dioxide/silicon-dioxide $\left(\mathrm{Pt} / \mathrm{SnO}_{2} / \mathrm{SiO}_{2}\right)$ catalysts, however additional catalysts that have shown high activity include catalysts utilizing platinum or gold $(\mathrm{Au})$ in combination with titanium dioxide $(\mathrm{TiO} 2)$, aluminum oxide $\left(\mathrm{Al}_{2} \mathrm{O}_{3}\right)$, manganese dioxide $\left(\mathrm{MnO}_{2}\right)$, and iron oxide supports $\left(\mathrm{FeO} \text { and/or } \mathrm{Fe}_{2} \mathrm{O}_{3}\right)^{3-6}$.

While the focus of this paper is on $\mathrm{CO}$ oxidation, in recent years there has been significant interest in the ambient temperature oxidation of $\mathrm{HCHO}$ targeting indoor air quality applications. Much of this work has identified platinum supported on tin oxide $(\mathrm{SnO} 2)$ or titanium dioxide $\left(\mathrm{TiO}_{2}\right)$ supports as the most promising. Since most short term NASA missions requiring trace contaminant control utilize activated charcoal for the adsorption of most of the organics, and the fact that formaldehyde requires specially treated, expendable sorbents, a catalyst that can perform ambient temperature oxidation of $\mathrm{CO}$ and $\mathrm{HCHO}$ is advantageous from a design perspective.

Gold catalysts, developed by TDA Research (TDA) and 3M Corporation (3M), and platinum based catalysts developed by Hamilton Sundstrand, have been evaluated in preliminary screening tests to measure the relative activity compared to the NASA ATCO baseline ambient temperature CO oxidation catalyst which is $2 \%$ platinum on activated carbon. Additionally, limited testing for HCHO oxidation was also conducted for some of the catalysts. While the testing reported in this paper is focused on the low concentrations associated with trace contaminant control, TDA and 3M have performed additional testing of their gold catalysts at elevated CO concentrations ranging 1,000-10,000 ppm, some of which has been previously published ${ }^{7}$.

\section{Discussion}

Catalyst screening tests were conducted at approximate concentrations of interest to trace contaminant control systems consistent with the historical design requirements of the U.S. space program. Basic design requirements consider two sources of contamination - the crew and the equipment. The generation rates for numerous contaminants, compiled over the history of the U.S space program, along with the space maximum allowable concentrations (SMAC), are summarized by Perry ${ }^{8}$. The SMAC values for CO and $\mathrm{HCHO}$ are listed as $17 \mathrm{mg} / \mathrm{m}^{3}$ $\left(15 \mathrm{ppm}, \mathrm{ppm}=\mathrm{mg} / \mathrm{m}^{3} \times 22.4\right.$ liter $/ \mathrm{mole} /$ molecular weight at $\left.0{ }^{\circ} \mathrm{C}\right)$ and $0.12 \mathrm{mg} / \mathrm{m}^{3}(0.1 \mathrm{ppm})$ respectively. Nominal concentrations used in the catalyst screening tests reported in this study were approximately $10 \mathrm{ppm}$ and $100 \mathrm{ppb}$, for $\mathrm{CO}$ and $\mathrm{HCHO}$ respectively.

\section{A. CO Oxidation Tests}

The test rig used for the $\mathrm{CO}$ oxidation studies is shown below in Fig. 1.

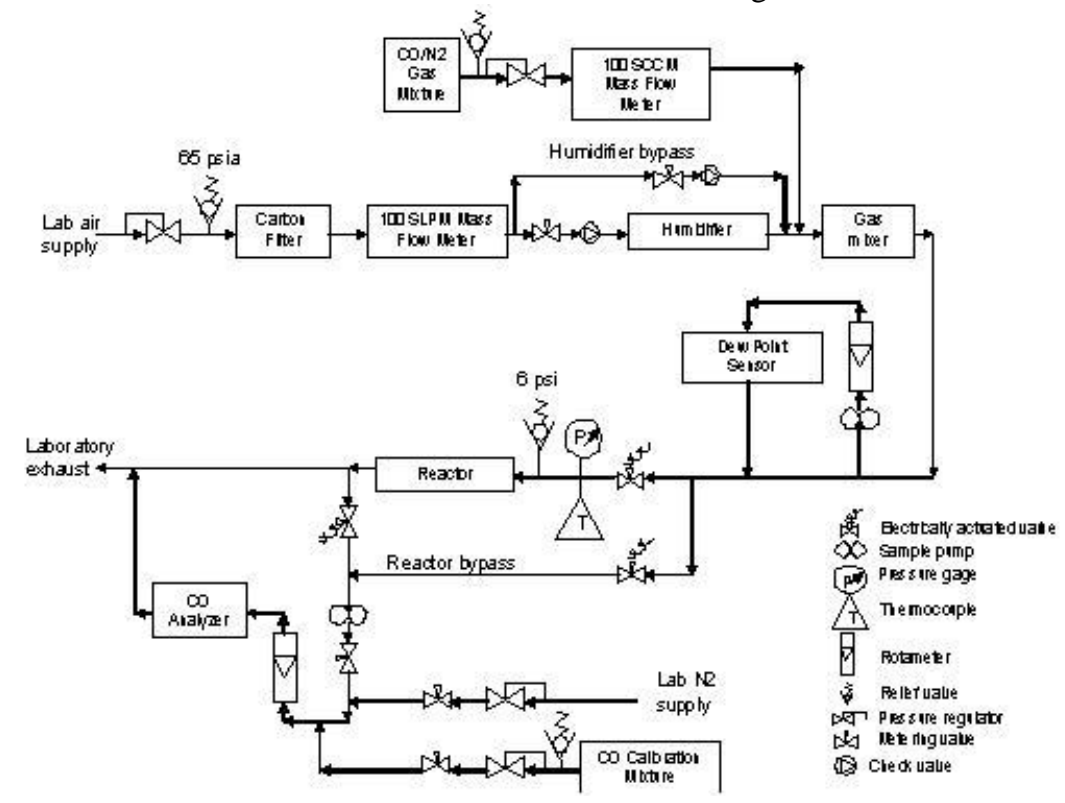

Figure 1.CO Oxidation Test Rig

2

American Institute of Aeronautics and Astronautics 
The concentration of $\mathrm{CO}$ is controlled by adjusting the flow rate of a high concentration $\mathrm{CO} /$ nitrogen supply which is subsequently mixed with filtered laboratory air prior to feeding the CO/air mixture to the reactor. The influent is then humidified by diverting part of the process air flow through the humidifier. Table 1 identifies the characteristics of the catalysts examined.

Table 1. Catalyst Characteristics

\begin{tabular}{|c|c|c|c|}
\hline Catalyst & Active Metal & Reactant & Support \\
\hline ATCO & $\mathrm{Pt}$ & $\mathrm{CO} / \mathrm{HCHO}$ & Carbon \\
\hline $\mathrm{HSPT} 1$ & $\mathrm{Pt}$ & $\mathrm{CO} / \mathrm{HCHO}$ & $\mathrm{TiO}_{2}$ \\
\hline $\mathrm{HSPT} 2$ & $\mathrm{Pt}$ & $\mathrm{CO} / \mathrm{HCHO}$ & $\mathrm{SiO}_{2}$ \\
\hline $\mathrm{STC}$ & $\mathrm{Pt}$ & $\mathrm{CO}$ & $\mathrm{SnO}_{2}$ \\
\hline $\mathrm{TDA} \mathrm{Au}$ & $\mathrm{Au}$ & $\mathrm{CO}$ & Proprietary \\
\hline $3 \mathrm{M} \mathrm{Au}$ & $\mathrm{Au}$ & $\mathrm{CO}$ & Proprietary \\
\hline
\end{tabular}

To determine an appropriate flow rate to be used in the CO screening tests, the current NASA ATCO reactor design point flow rate and catalyst volume was used for scaling, which resulted in a gas hourly space velocity (GHSV) of 2,500 $\mathrm{hr}^{-1}$. However, at this space velocity the conversion of all catalysts was $100 \%$ for 5 days and therefore a relative comparison could not be made. To address this, the GHSV was increased until a conversion less than $100 \%$ was measured. A GHSV of $110,400 \mathrm{hr}^{-1}$ was determined sufficient to result in a measurable range of conversions for the various catalysts. All of the catalysts were initially tested in the "as received" form and particle size, with the exception of the TDA Au catalyst which was sieved to remove fines. The initial performance comparison utilized a volume of $15 \mathrm{cc}$ for each of the catalysts tested. The results for the initial screening tests for the various catalysts in dry air at 10 ppm CO are shown in Fig. 2.

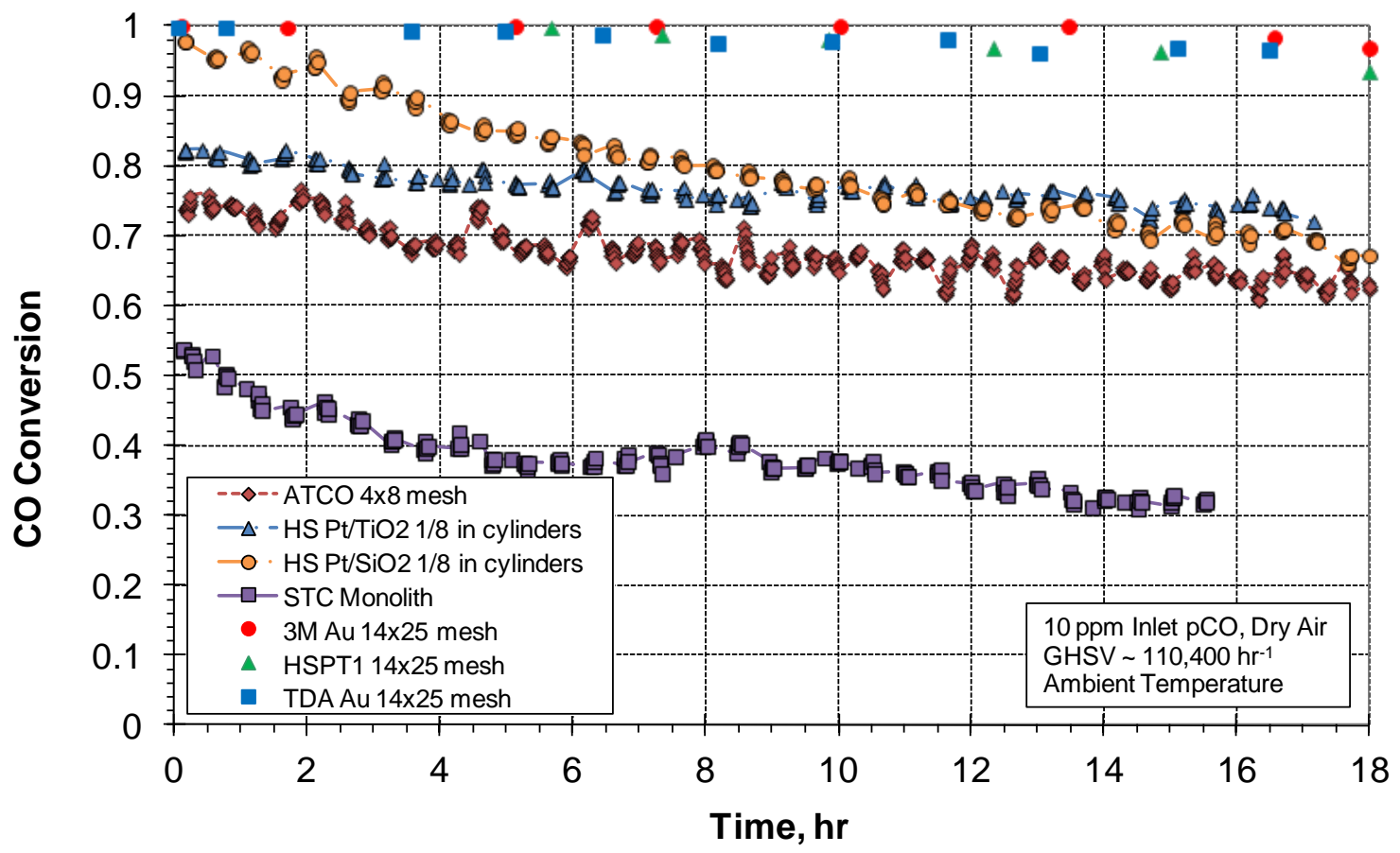

Figure 2. Relative Activity of CO Oxidation Catalysts for Trace Contaminant Control Applications at GHSV of 110,400 hrs ${ }^{-1}$, 10ppm Inlet CO, in Dry Air

3

American Institute of Aeronautics and Astronautics 
Figure 2 shows that most of the catalysts tested indicated higher activities for $\mathrm{CO}$ oxidation than the NASA baseline.

The STC Catalysts, Inc. (STC) monolith catalyst had the lowest conversion of all of the catalysts shown which is primarily assumed to be a result of lower active metal content per unit volume of catalyst, though the specific formulation was not available from the manufacturer.

As can be seen in Fig. 2, particle size has a significant effect on the activity of the platinum catalyst HSPT1, and though not measured experimentally, it is assumed that this would be true for the other catalysts tested. This is due to the high intrinsic $\mathrm{CO}$ oxidation reaction rate being much higher than the diffusion rate of $\mathrm{CO}$ within the catalyst structure. To be able to distinguish the relative activities of the $14 \times 25$ mesh catalysts, a higher space velocity $\left(1,850,000 \mathrm{hr}^{-1}\right)$ and higher CO concentration (40 ppm) were tested and the results shown in Fig. 3.

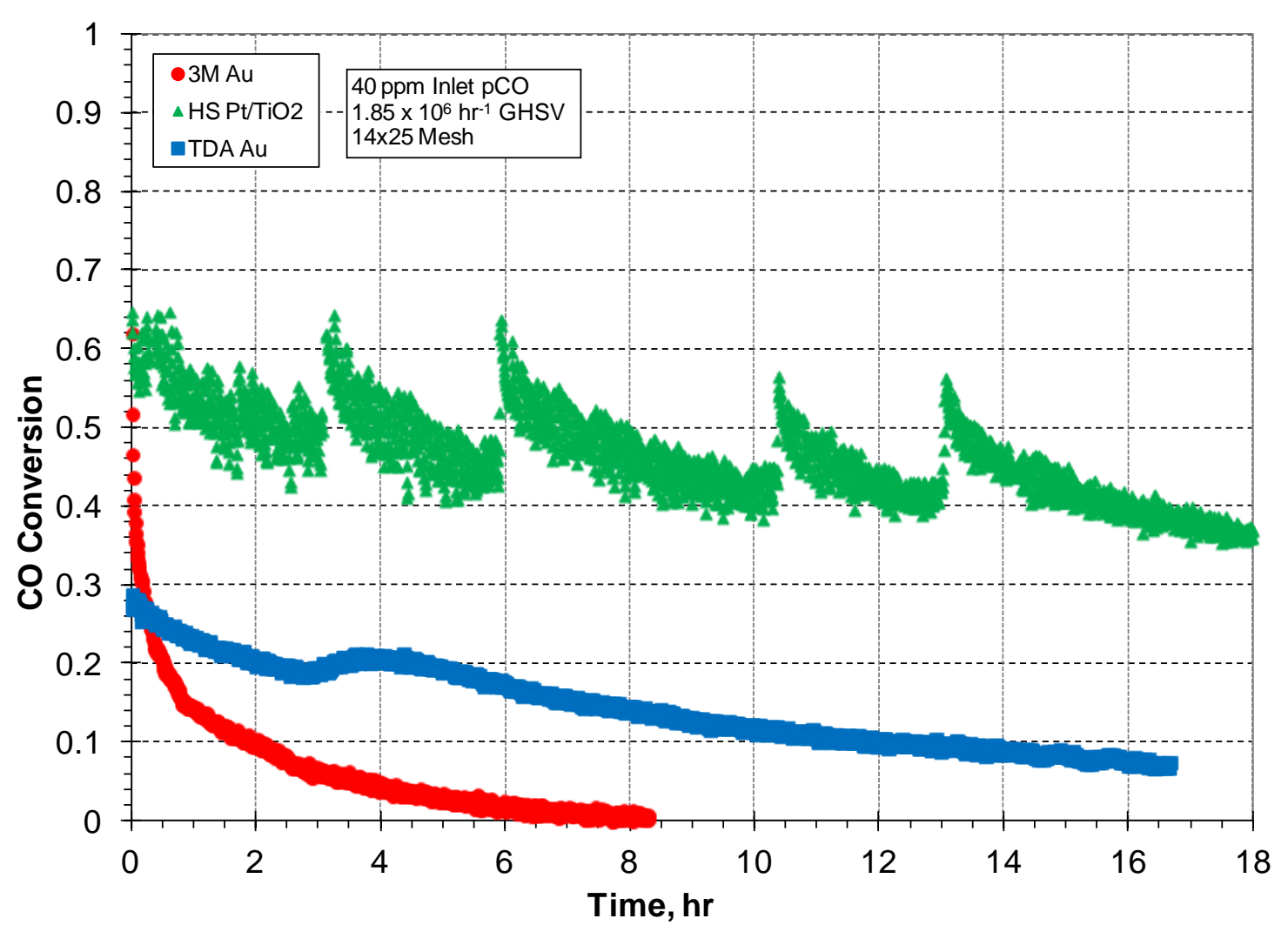

Figure 3. Relative Activity of $14 \times 25$ mesh CO Oxidation Catalysts at GHSV of 1,850,000 hrs ${ }^{-1}, 40 p p m$ Inlet CO, in Dry Air

The oscillations noted for the platinum catalyst are consistent with similar observations for CO oxidation reported in the literature and is attributed to a periodic "restructuring" of the active species which are adsorbed on the platinum ${ }^{9-10}$.

The effect of relative humidity was investigated in two separate tests due to the differences in conversion as a result of particle size. The larger catalyst particles, resulting in the lower conversions shown in Fig. 2, were tested at a GHSV of 110,400 $\mathrm{hr}^{-1}$, whereas the smaller catalyst particles were tested at higher space velocities and a higher $\mathrm{CO}$ concentration to provide some resolution of the relative activity of the catalysts. The results of these tests are 
shown in Fig. 4 and Fig. 5. The HSPT1 14x25 mesh platinum catalyst resulted in 100\% conversion at a GHSV of $160,000 \mathrm{hr}^{-1}$ but was not tested at 240,000 $\mathrm{hr}^{-1}$.

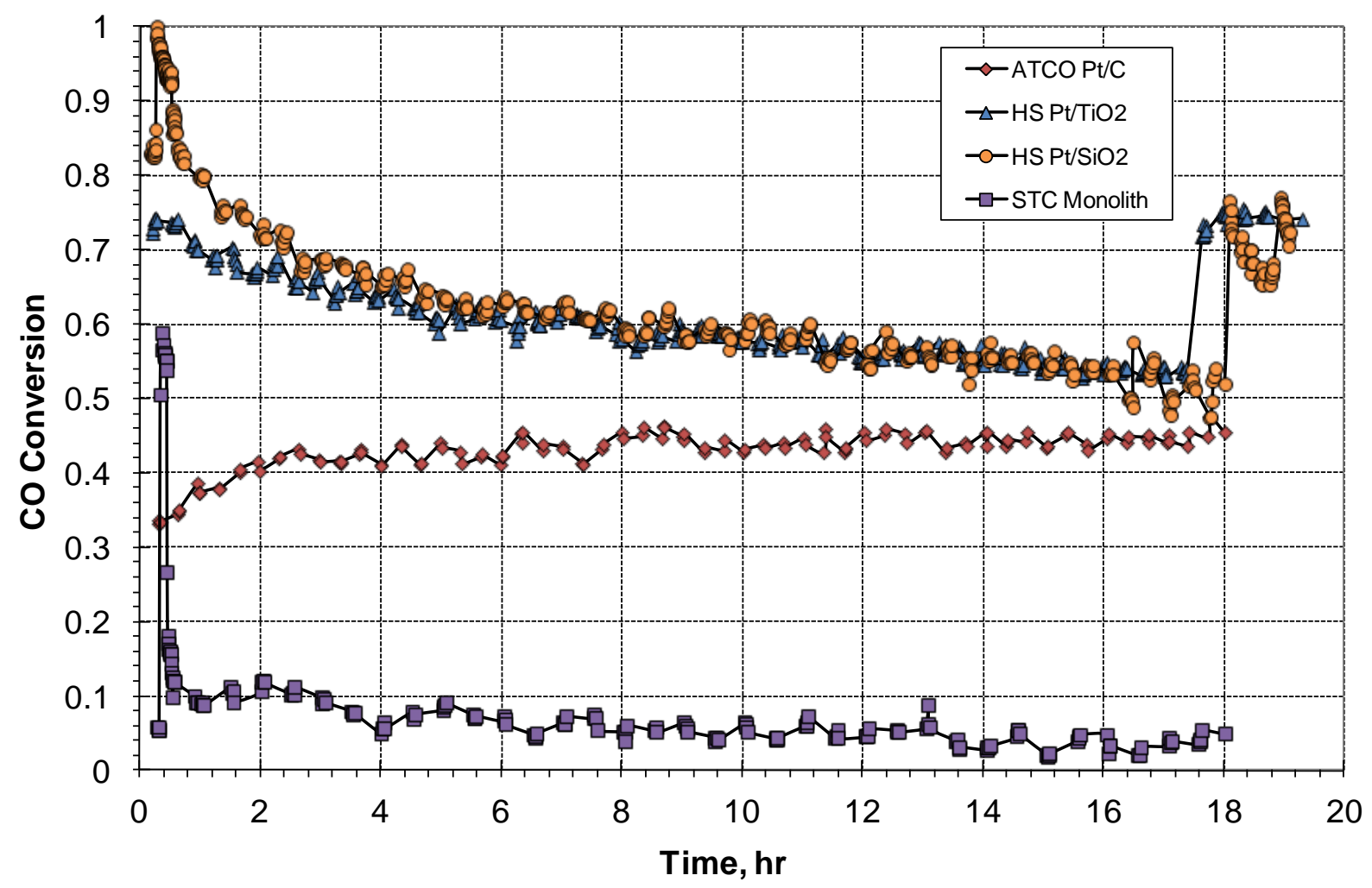

Figure 4. Relative Activity of Larger Particle CO Oxidation Catalysts for Trace Contaminant Control at a GHSV of $110,400 \mathrm{hr}^{-1}$ at $50 \%$ Relative Humidity (transient performance at beginning and end of test due to humidification bypass) 


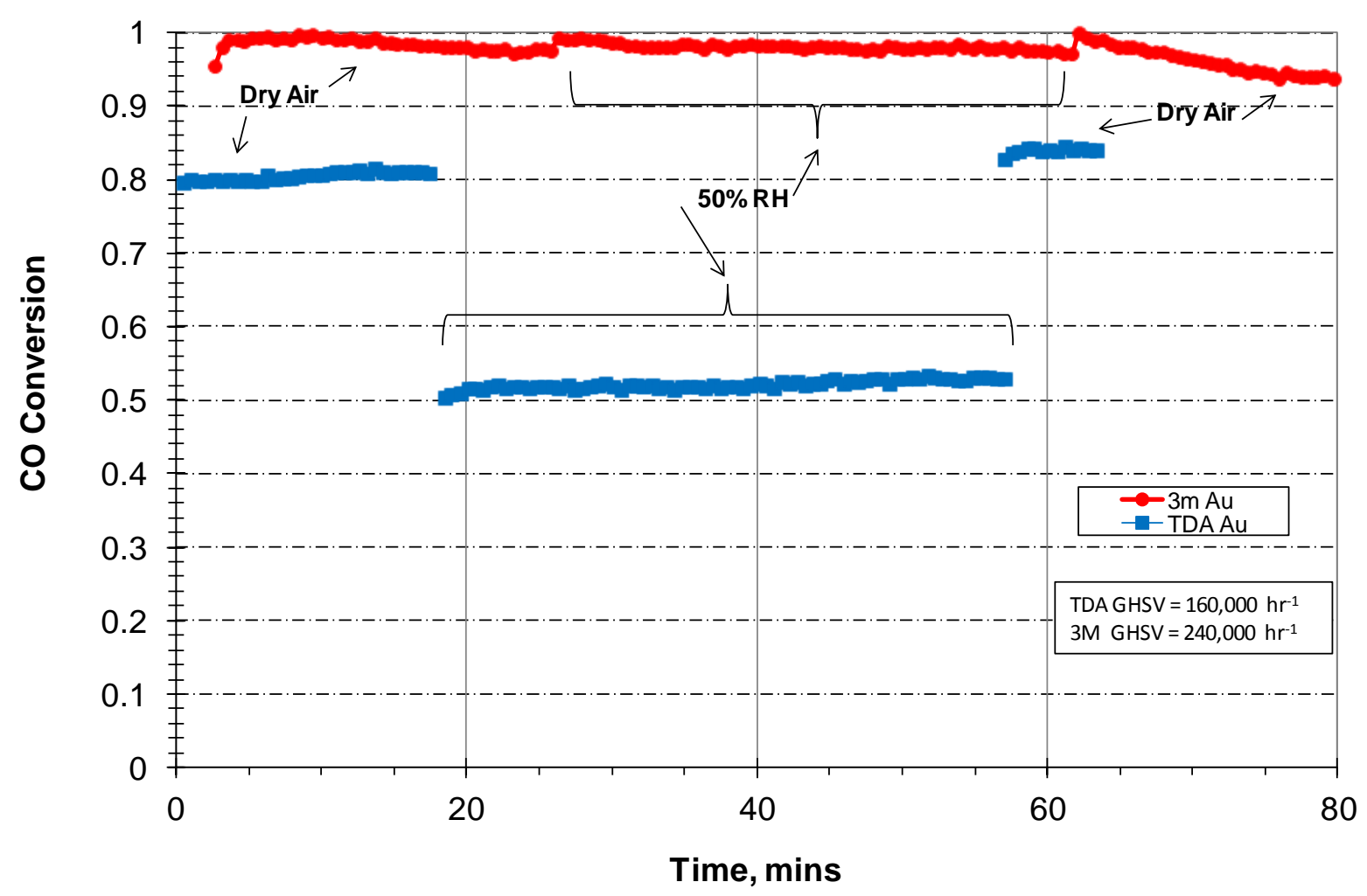

Figure 5. Relative Activity of $14 x 25$ mesh Au CO Oxidation Catalysts for Trace Contaminant Control
Applications at Various GHSV, 40ppm Inlet CO, at 50\% Relative Humidity

At the conditions shown for the two gold catalysts in Fig. 5, the 3M catalyst showed minimal effect due to the presence of water vapor, even with a 50\% increase in GHSV, whereas the conversion of the TDA catalyst decreased approximately $38 \%$. It is interesting to note that at higher space velocities in dry air, the TDA gold catalyst had a higher conversion compared with the 3M catalyst as noted in Fig. 3. This could be due to two factors. First, the active metal content of the $3 \mathrm{M}$ catalyst may be lower than TDA's and therefore at the higher space-velocity there are insufficient active sites to sustain the high reaction rate. Secondly, it is possible that due to the shorter duration of the tests conducted in the presence of water vapor, that the higher activity observed for the $3 \mathrm{M}$ catalyst is a result of its high initial activity (as seen in the dry testing) and if run for a longer test period, a decrease in activity would have been observed.

\section{B. HCHO Oxidation Tests}

The HCHO oxidation test set-up accommodated simultaneous testing of all candidate catalysts, using a series of 3-way valves on the outlet of each reactor to select the individual reactors for HCHO analysis of the effluent. A single, common synthetic air stream $(20 \%$ O2, 80\% N2) was used in all tests. Formaldehyde was generated by vaporizing paraformaldehyde. Formaldehyde generation was based on controlled diffusion of formaldehyde vapor. The formaldehyde generator consists of a vial, in which a quantity of paraformaldehyde was deposited, a diffusion tube attached to the vial, a containment vessel and a temperature controlled water bath. The vial is secured inside the containment vessel which is immersed in the water bath. Nitrogen carrier gas, preheated to the water bath operating temperature, enters the containment vessel and sweeps away formaldehyde from the end of the diffusion tube/vial before finally leaving the containment vessel. Humidity levels were controlled by passing part of the flow stream 
though a bubbler followed by dilution with the balance of the flow stream and mixed prior to entering the bank of reactors. The HCHO test rig schematic is shown below in Fig. 6.

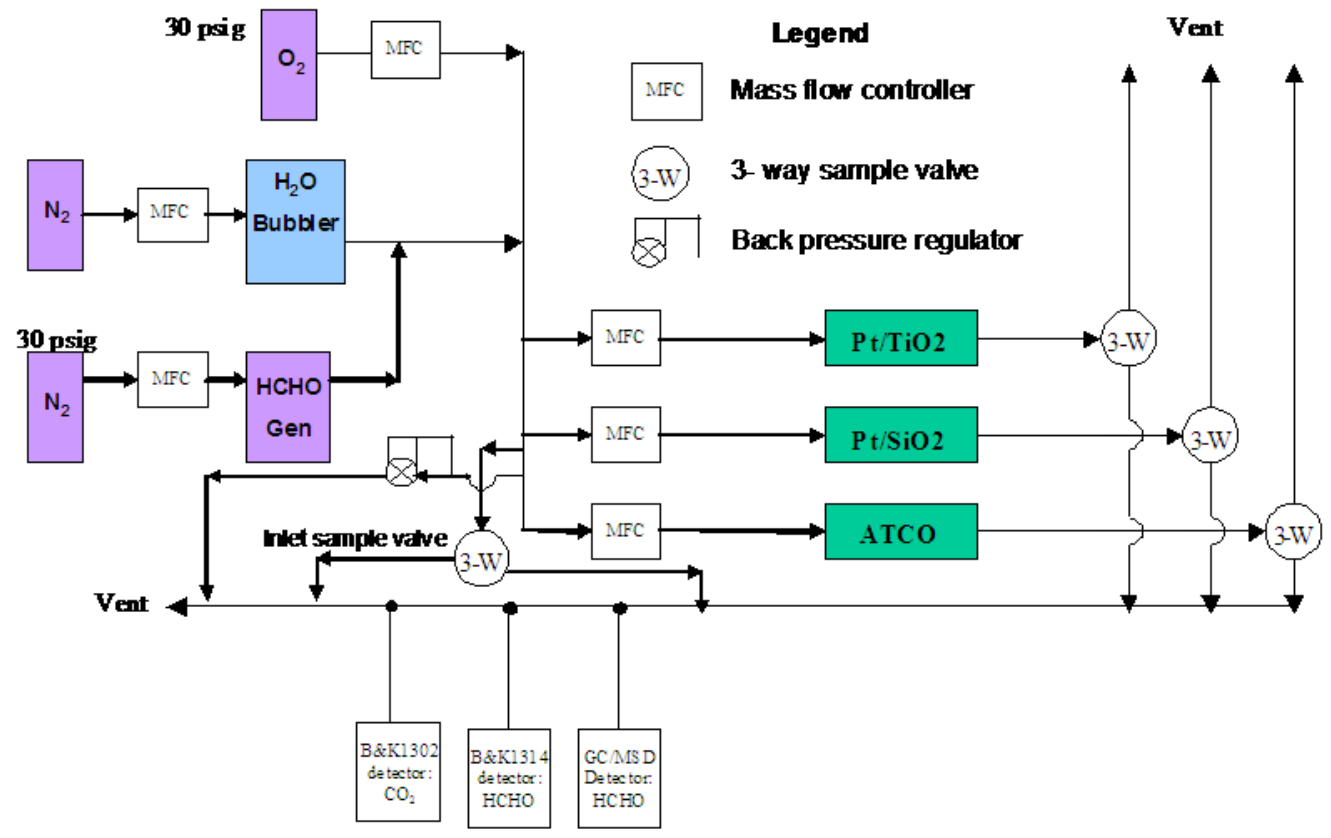

Figure 6. Detailed Schematic of HCHO Oxidation Test Rig

HCHO testing was conducted only on the "as received" larger granule size platinum catalyst. These tests were not conducted on the STC catalyst due to its low activity with respect to CO oxidation while the 3M and TDA gold catalysts were not available at the time of this study.

HCHO screening tests were conducted at GHSVs ranging from 6,000-120,000 $\mathrm{hr}^{-1}$. Tests were conducted in dry air and at $30 \% \mathrm{RH}$, all at ambient temperature. Most of the tests were conducted at an inlet $\mathrm{HCHO}$ concentration of approximately $100 \mathrm{ppb}$ while one test was conducted at an inlet $\mathrm{HCHO}$ concentration of approximately $300 \mathrm{ppb}$ at a GHSV of $120,000 \mathrm{hr}^{-1}$. Since no significant deactivation was noted during the testing, the same catalyst was used for all tests. Moisture was introduced between hours 375 and 500. Results for the various tests are shown for the three catalysts in Figs. 7-9. 


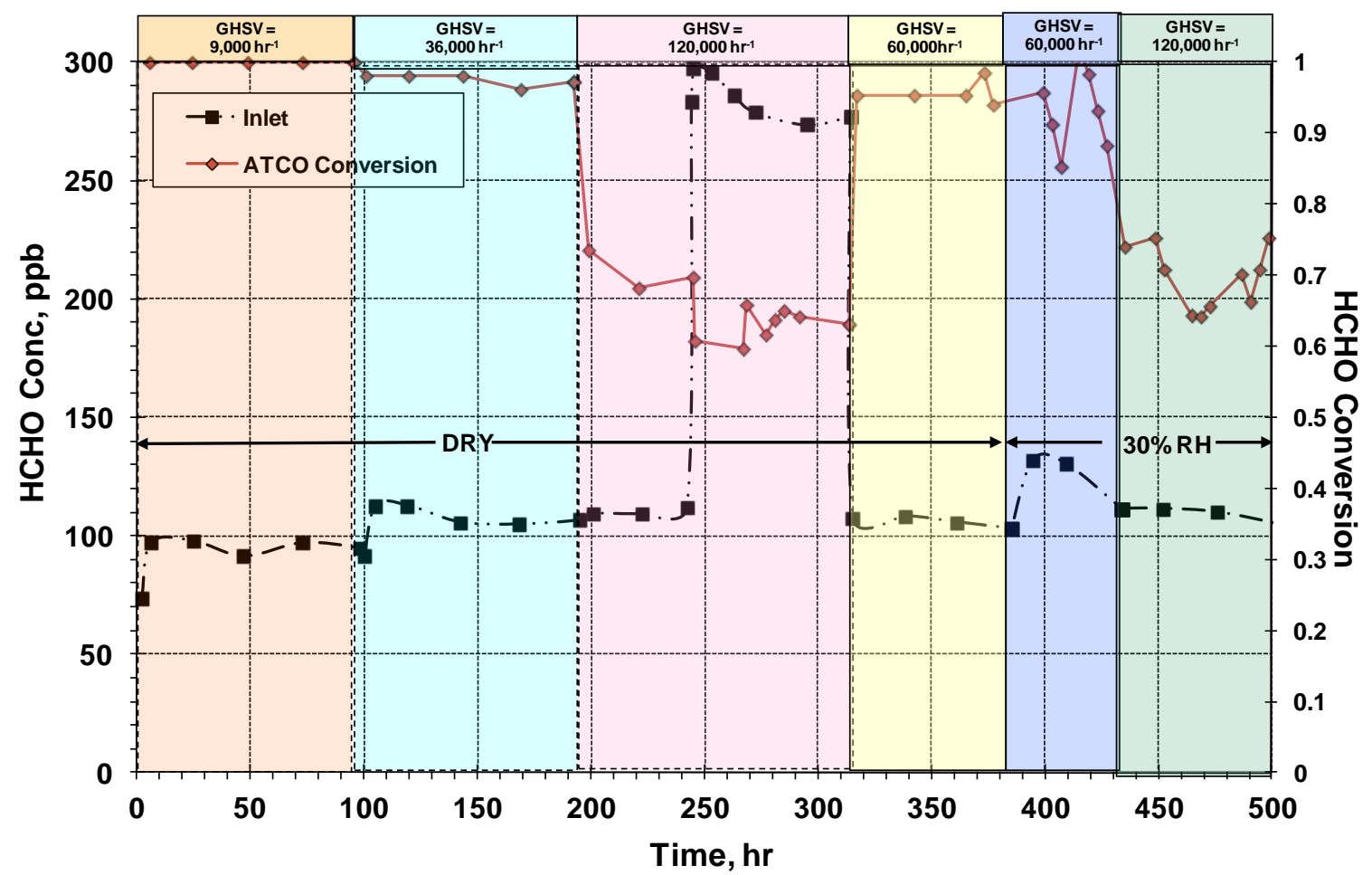

Figure 7. Screening Test for HCHO Oxidation on ATCO Catalyst

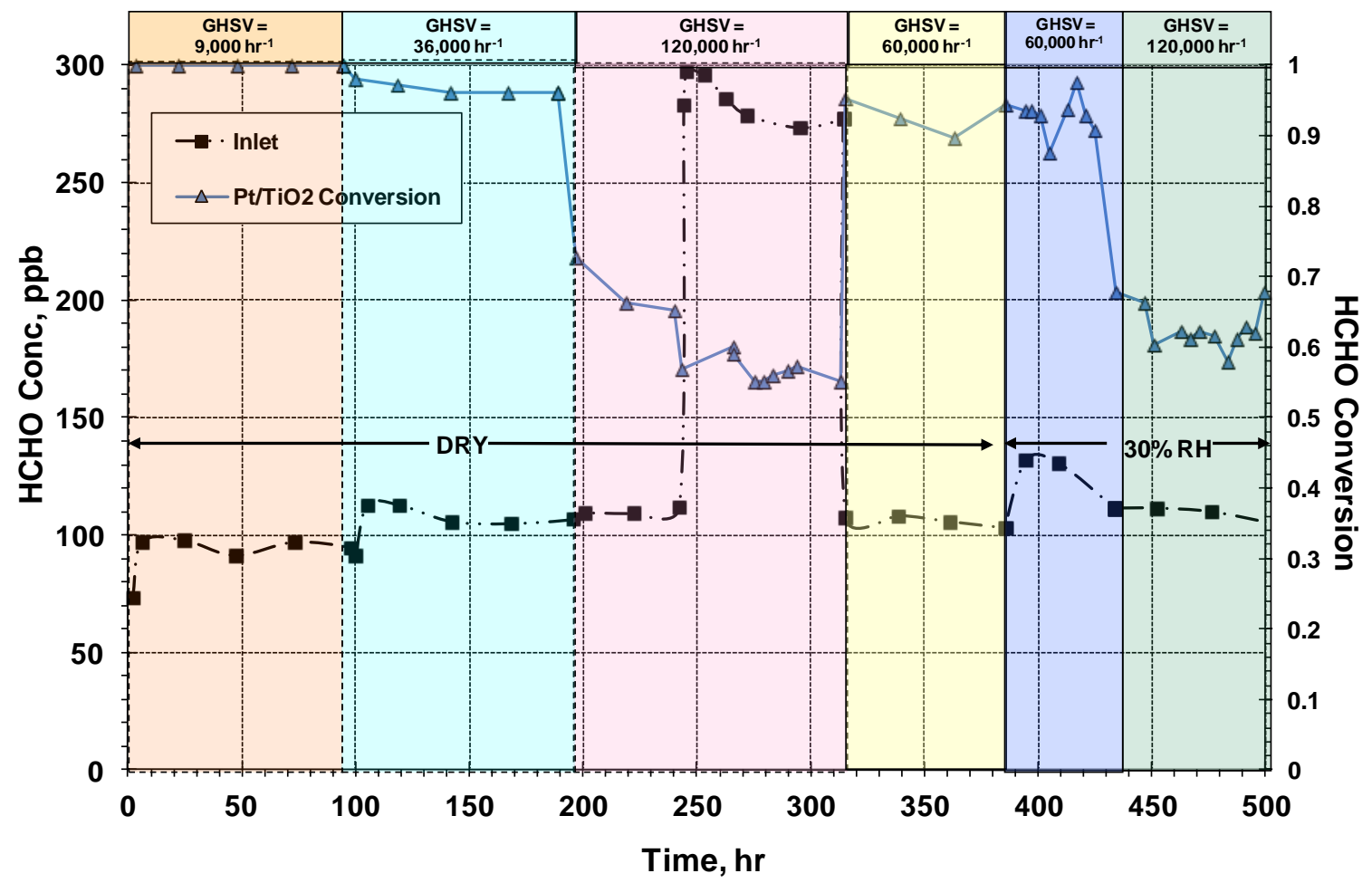

Figure 8. Screening Test for HCHO Oxidation on HSPT1 1/8" Cylinder Catalyst 


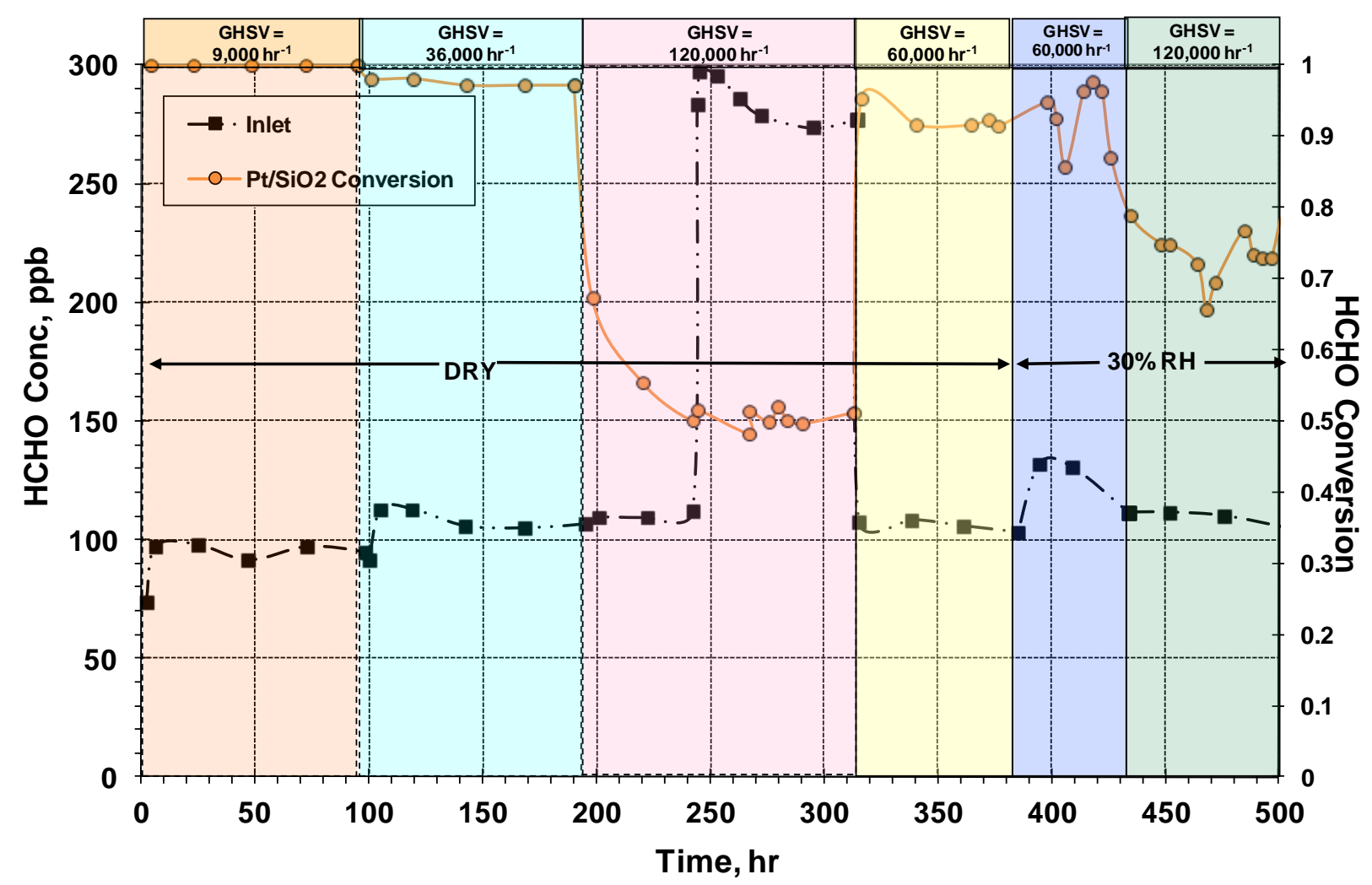

Figure 9. Screening Test for HCHO Oxidation on HSPT2 1/8" Cylinder Catalyst

For the three catalysts tested, there were no significant differences noted in performance over the range of conditions tested. At high space velocities, the dry HSPT2 performance was slightly lower than the others, however with the introduction of moisture, the oxidation efficiency increased to levels consistent with the others. In general the effect of moisture was relatively small and not as pronounced as in the $\mathrm{CO}$ oxidation screening tests. Upon changing the inlet $\mathrm{HCHO}$ concentration to $300 \mathrm{ppb}$, at approximately 250 hours into the test, there was no significant change in conversion.

In addition to the oxidation efficiency, the outlet $\mathrm{CO}_{2}$ concentration was also measured to allow for a mass balance to verify complete oxidation of the $\mathrm{HCHO}$ to $\mathrm{CO}_{2}$ and water without the formation of intermediate species. The outlet $\mathrm{CO}_{2}$ concentrations for the three catalysts are shown below in Fig. 10 and shows that the HCHO is completely oxidized to $\mathrm{CO}_{2}$ within expected experimental accuracy. For complete oxidation of $\mathrm{HCHO}$, the outlet $\mathrm{CO}_{2}$ concentration should be identical to the inlet $\mathrm{HCHO}$ concentration. The initial lower than expected $\mathrm{CO}_{2}$ concentration is believed to be due to an initial adsorption of the $\mathrm{CO}_{2}$ and/or $\mathrm{HCHO}$ as the surface species come to equilibrium on the catalyst surface, whereas the spike noted at approximately 80 hours into the test can be traced to an approximate $5^{\circ} \mathrm{C}$ increase in ambient temperature, most likely resulting in desorption of adsorbed $\mathrm{CO}_{2}$ from the catalysts. 


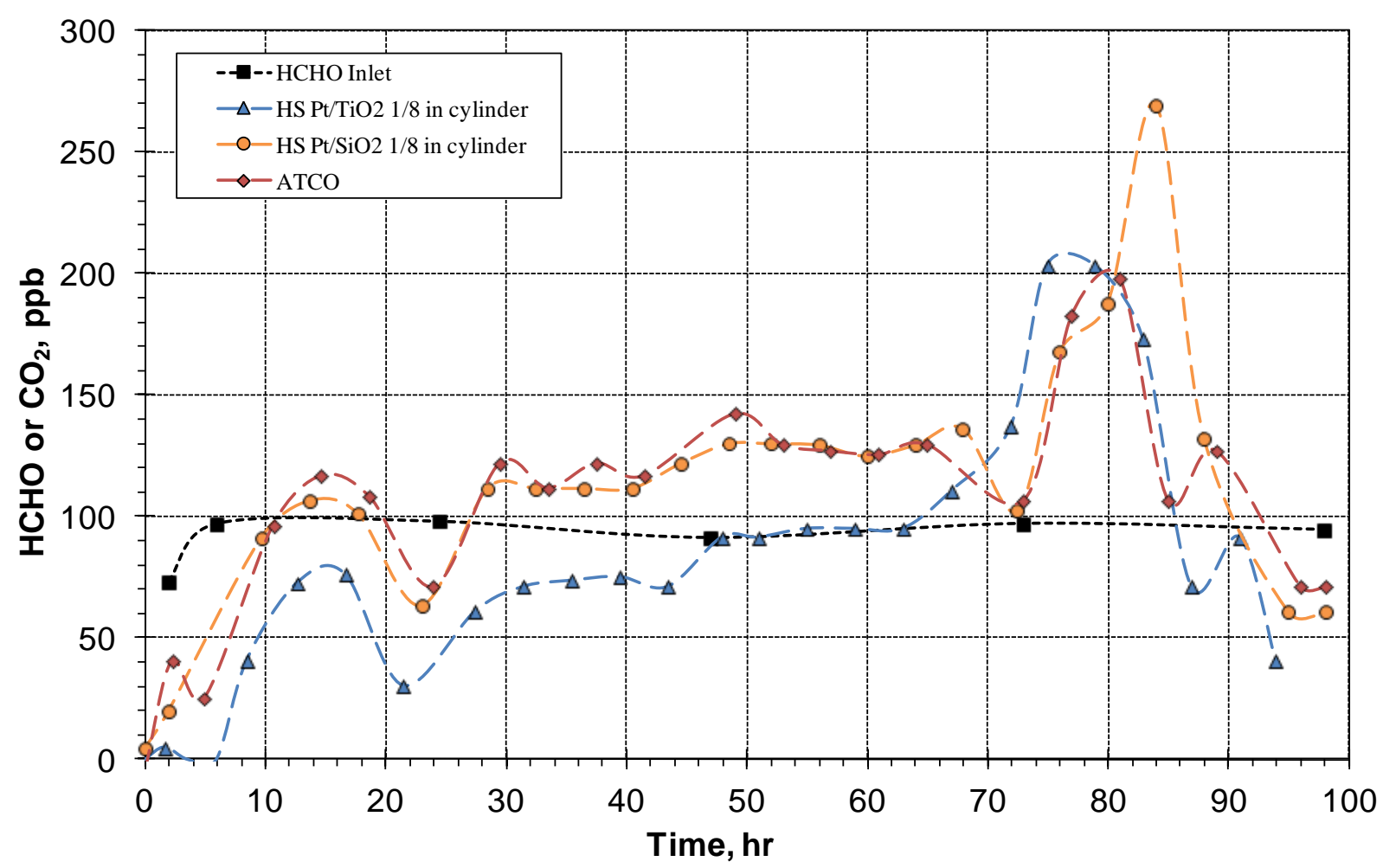

Figure 10. Carbon Mass Balance during $\mathrm{HCHO}$ Oxidation - Effluent $\mathrm{CO}_{2}$ Concentration

\section{Conclusion}

For all the catalysts tested for CO oxidation at the nominal Shuttle design space velocity, $100 \%$ conversion was obtained for 5 days indicating that there is most likely significant margin in the current ATCO reactor. For the catalysts tested, the platinum catalyst were more active than gold catalysts, and a significant internal mass transfer resistance is demonstrated through the testing of smaller catalyst particles, indicating that additional enhancements are possible assuming that any increased pressure drop resulting from smaller particles can be addressed using appropriate reactor design. Additionally, catalyst supports with more open structures (higher effectiveness factor) may also warrant future investigation to reduce the required amount of catalyst.

The Pt-based catalysts were more active than the Au-based catalysts at high space velocity. While the TDA Aubased catalyst was more active than the $3 \mathrm{M}$ catalyst in dry air, the $3 \mathrm{M}$ catalyst was less susceptible to moisture than the TDA catalyst. Additional testing is warranted to determine if the $3 \mathrm{M}$ catalyst's performance under humid conditions is sustained for longer periods of time.

All of the platinum catalysts demonstrated similar activities for $\mathrm{HCHO}$ oxidation, with $100 \%$ conversion at $100 \mathrm{ppb}$ inlet concentrations up to a GHSV of $60,000 \mathrm{hr}^{-1}$, with the conversion dropping to approximately $50 \%$ at a GHSV of $120,000 \mathrm{hr}^{-1}$. Minimal effect of moisture was noted at $30 \% \mathrm{RH}$ for the HCHO oxidation on the platinum catalysts.

Based on the higher activity resulting from particle size for the platinum catalyst, a higher effectiveness catalyst would reduce bed size, though the potential impact on $\mathrm{HCHO}$ has not been validated.

In summary, advanced platinum and gold catalysts have demonstrated significantly higher ambient temperature oxidation efficiency for CO than the NASA baseline ATCO catalyst, and the platinum catalysts have demonstrated activity for ambient temperature oxidation of HCHO. 


\section{Acknowledgments}

The authors would like to thank the 3M Corporation for graciously providing gold catalyst samples used in this study and Tim Obee of the United Technologies Research Center for his extensive support in the conduct of the formaldehyde oxidation test studies.

\section{References}

${ }^{1}$ Hoflund, G.B., Gardner, S.D., 1995. Effect of $\mathrm{CO}_{2}$ on the Performance of Au/MnOx and Pt/SnOx/SiO2 Low Temperature CO Oxidation Catalysts. Langmuir, 11, pp. 3431-3434.

${ }^{2}$ STC Catalysts Inc. Available from www.stc-catalysts.com [Accessed December, 2007].

${ }^{3}$ Haruta, M., 2003. When Gold Is Not Noble: Catalysis by Nanoparticles. The Chemical Record, 3, pp.75-87.

${ }^{4}$ Bond, G.C., Thompson, D.T., 2000. Gold- Catalyzed Oxidation of Carbon Monoxide. Gold Bulletin, 33(2), pp.41-51.

${ }^{5} \mathrm{Xu}, \mathrm{C} ., \mathrm{Xu}, \mathrm{X}$., Su, J., Ding, Y., 2007. Research on unsupported nanoporous gold catalyst for CO oxidation. Journal of Catalysis, 252, pp. 243-248.

${ }^{6}$ Aguilar-Guerrero, V., Gates, B. C., 2009. Kinetics of CO Oxidation by Supported Gold: A Tabular Summary of the Literature. Catalysis Lett, 130, pp. 108-120.

${ }^{7}$ Alptekin, G., Cates, M., Dubovik, M., Cesario, M., 2008. The Smoke Eater, A Sorbent/Catalyst for Recovery from Fires. ICES 2008-01-2098, San Francisco, CA.

${ }^{8}$ Spacecraft Maximum Allowable Concentrations for Airborne Containments. JSC-20584. Nov. 2008.

${ }^{9}$ Eiswirth, M., Ertl, G., 1986. Kinetic oscillations in the catalytic CO oxidation on Pt(100) surface. Surf. Sci. 177, pp. $90-100$.

${ }^{10}$ McCarthy, E., Zahradnik, J., Kuczynski, G., Carberry, J., 1975. Some Unique Aspects of CO Oxidation on Supported Pt. Journal of Catalysis, 39, pp.29-35. 